\title{
ANALISIS PENGARUH KEPUTUSAN INVESTASI MAHASISWA
}

\author{
Lilis Ayudiastuti \\ Universitas Negeri Surabaya \\ lilisayudiastuti@gmail.com
}

\begin{abstract}
In Indonesia, the capital market experiences very rapid growth. The increase of the IDX Composite in 2016 was an indicator of capital market developments and affects investment activities. The investment activities related to the investment judgments of investors are affected by many factors. This study discusses the impact of financial literacy, herding behaviour, risk perception, overconfidence, experience regret, and the illusion of control on investment decisions. This study used 100 equity investors registered in an investment gallery at the Universitas Nusantara PGRI Kediri as samples. The analysis technique is SEM PLS. Results show that financial literacy, overconfidence, and illusion of control affect investment decisions. Besides, herding behaviour, risk perception, and experience regret do not influence investment decisions. The significance of these findings is to provide knowledge about the aspects and factors that influence investment decisions. Financial literacy allows investors to gain more information and learn about investments to avoid and prevent risks. Overconfidence gives investors sufficient certainty and information in making decisions by paying attention to the risks to prepare themselves to receive returns from the undertaken investments. The illusion of control makes investors believe in their abilities which can trigger investment results. Students with better financial knowledge can make better investment decisions.
\end{abstract}

Keywords: financial literacy; herding behavior; illusion of control; investation decision; risk perception.

\section{PENDAHULUAN}

Pasar modal merupakan satu dari kegiatan ekonomi dunia yang penting pada abad 21. Perusahaan banyak yang listing di Bursa Efek menggunakan pasar modal sebagai sarana menarik investasi untuk memerkuat posisi keuangan perusahaan tersebut. Pasar modal berperan sebagai perantara bagi investor dan perusahaan maupun instansi pemerintah melalui transaksi instrumen keuangan (Lliyd, 1976).

Di Indonesia sendiri pasar modal mengalami pertumbuhan yang sangat pesat.Tahun 2018, jumlah Indeks Harga Saham Gabungan (IHSG) mengalami kenaikan sebesar 4,4\% dari posisi 6.194,50 menjadi 6.468,76 pada 2019. Hal ini menjadi indikator dari perkembangan pasar modal (Liputan6.com, 2019). Perkembangan pasar modal saat ini dapat memberikan kesempatan dan return yang tinggi dari kegiatan investasi di pasar modal. Hal seperti ini dapat menjadikan pasar modal Indonesia menjadi salah satu daya tarik untuk investor mancanegara maupun investor Indonesia. Perkembangan terkait jumlah IHSG diikuti dengan naiknya jumlah investor pasar modal di Indonesia. Data statistik publik yang dikeluarkan oleh PT Kustodian Sentral Efek Indonesia (KSEI) bulan Januari 2021 menunjukkan peningkatan jumlah investor pasar modal yang signifikan. Data pada akhir tahun 2018 hingga akhir tahun 2019 menunjukkan kenaikan jumlah investor dari 1.619 .372 menjadi 2.484.354. Peningkatan sebesar 53,41\% ini masih lebih rendah dari data akhir tahun 2019 hingga 2020. Akhir tahun 2020, jumlah investor sudah mencapai 3.880.753 (DJKN, 2021). Peningkatan investor perorangan merupakan upaya Bursa Efek Indonesia (BEI) bekerja bersama Perguruan Tinggi membangun Galeri Investasi (GI). Hal tersebut sebagai strategi untuk mengajak masyarakat dalam konteks ini adalah mahasiswa agar berinvestasi pada pasar modal (Salerindra, 2020). Di Jawa Timur, alokasi persebaran investor pasar modal meliputi banyak kota yaitu Surabaya 48.626 SID, Malang 15.498 SID, Sidoarjo 12.768 SID, Kediri 6.758 SID, Gresik 4.809 SID, Jember 4.102 SID, Madiun 3.927 SID, Mojokerto 3.289 SID, Jombang 3.058 SID, Banyuwangi 2.832 SID. Data alokasi persebaran investor menunjukkan jumlah investor pasar modal di Kediri masih rendah, padahal jumlah galeri investasi cukup memadai yaitu sebanyak 4 galeri investasi (Bisnis.com, 2020). 
Otoritas Jasa keuangan terus berupaya menambah jumlah Galeri Investasi agar memenuhi peningkatan minat masyarakat dalam berinvestasi. Perkembangan dunia investasi yang begitu pesat menjadikan permintaan investasi masyarakat terus meningkat. Masyarakat meyakini akan mendapatkan penghasilan tambahan dengan berinvestasi. Financial literacy memiliki peran penting dalam pemahaman produk investasi. Diharapkan dengan penguasaan financial literacy yang baik, masyarakat khususnya investor dapat mengambil keputusan investasi yang tepat sesuai ekspektasi, yaitu memperoleh keuntungan (Budiarto, 2017). Namun, berbeda dengan peningkatan financial literacy di atas, hasil penelitian nasional oleh Otoritas Jasa Keuangan (OJK) terhadap financial literacy di Indonesia pada tahun 2013 menyatakan 21,84\% responden yang dapat diklasifikasikan sebagai well literate. Jadi hanya sebagian kecil pelaku pasar modal di Indonesia yang benar-benar memahami produk investasi, dasar-dasar dan sistem pasar modal (OJK, 2015).

Organization for Economic Co-operation and Development (2016) menyebutkan financial literacy adalah pemahaman, pengetahuan, keterampilan terkait konsep dan risiko keuangan serta kepercayaan diri dan motivasi ketika membuat sistematika keuangan yang efektif, memajukan kesejahteraan keuangan masyarakat maupun individu, serta mengikuti kegiatan terkait perekonomian. Penelitian yang dilakukan oleh Nasional Literasi dan Inklusi Keuangan menunjukkan indeks literasi keuangan tahun 2016 ialah 29,7\% dan meningkat sebesar 21,8\% pada tahun 2013 (OJK, 2018). Penelitian oleh Wardani \& Lutfi (2019), Putra et al. (2016), danAren \& Zengin (2016) menunjukkan financial literacy berpengaruh terhadap keputusan investasi. Tetapi penelitian lain oleh Putri \&Isbanah (2020) dan Budiarto (2017) menunjukkan bahwa financial literacy tidak berpengaruh terhadap keputusan berinvestasi.

Menurut Anindya \& Sukamulja (2017), herding behavior merupakan perilaku ikut-ikutan di mana seorang investor mengikuti investor lain dengan berbagai alasan dan kondisi. Perilaku herding sering dilakukan di mana investor cenderung mengikuti sebagian besar investor lain saat mengambil sebuah keputusan berinvestasi. Pengaruh dari investor di sekitarnya menjadi penyebab bagi investor mempunyai sikap herding. Orang yang memiliki sikap herding gampang dipengaruhi oleh keputusan individu lain serta dapat memengaruhi perubahan keputusan investasi yang dibuat (Gozalie \& Anastasia, 2015). Berdasarkan penelitian yang dilakukan Putri \&Isbanah (2020), Khairunizam \& Isbanah (2019), dan Novianggie \& Asandimitra (2019), herding behavior memengaruhi keputusan investasi. Sedangkan, hasil berbeda dari Setiawan et al. (2018), Salerindra (2020), dan Bakar \& Yi (2016) menunjukkan herding behavior tidak memengaruhi keputusan investasi.

Faktor ketiga yang akan diteliti yaitu risk perception. Risk perception merupakan proses persepsi investor, evaluasi dan interpretasi risiko terhadap instrumen investasi terkait dengan keputusan investasi (Irjayanti, 2017). Menurut faktor psikologis pribadi, penilaian risiko masing-masing investor berbeda. Sindhu \& Kumar (2014) menyebutkan, risk perception adalah keyakinan individu, kelompok maupun masyarakat terhadap risiko dan waktu kemungkinan atau dampak risiko, baik rasional maupun irasional.

Menurut Pompian (2006), overconvidence adalah sikap percaya yang tidak memiliki alasan baik dari segi penalaran intuitif, penilaian, dan kemampuan kognitif seseorang. Overconvidence berasal dari pengujian dan survei psikologi kognitif, menyebutkan bahwa subjek membesar-besarkan kemampuan dalam prediksi dan keakuratan informasi yang mereka diberikan.

Menurut Yohnson (2008), experience regret adalah pengalaman yang membuat seseorang merasa menyesal dan kecewa dalam mengambil keputusan investasi, bahkan menerima risiko dari hasil keputusan investasi sebelumnya. Experience regret menjadikan investor akan berhati-hati ketika berinvestasi pada jenis investasi dengan risiko tinggi dan pengembalian tinggi, dan akan menghitung lebih dulu risiko yang timbul dari investasi yang dipilih. Artinya, seseorang yang mempunyai experience regret condong memilih investasi berisiko rendah karena memiliki pengalaman investasi kurang baik. 
Menurut Langer (1975), illusion of control merupakan harapan probabilitas keberhasilan diri sendiri yang secara tidak tepat lebih tinggi daripada probabilitas obyektif yang akan dijamin. Menurut Pompian (2006), illusion of control merupakan kecenderungan untuk percaya bahwa kita dapat mengendalikan atau setidaknya memengaruhi hasil, tetapi pada kenyataannya tidak dikendalikan. Berdasarkan hasil penelitian oleh Pradikasari \& Isbanah (2018) dan Salerindra (2020) menunjukkan illusion of control tidak memengaruhi keputusan investasi. Hasil berbeda ditunjukkan oleh Widiar Pradhana (2018) dan Kartini \& Nugraha (2015) mengemukakan illusion of control memengaruhi keputusan berinvestasi.

Penelitian ini bertujuan menganalisis pengaruh financial literacy, herding behavior, risk perception, overconvidence, experience regret, dan illusion of control terhadap keputusan investasi mahasiswa.

\section{KAJIAN PUSTAKA DAN PENGEMBANGAN HIPOTESIS}

\section{Decision Theory}

Decision theory adalah teori terkait pengambilan keputusan individu maupun kelompok dan digunakan di semua bidang. Dalam proses pengambilan keputusan, seseorang dihadapkan dengan tiga kondisi sebagai berikut kondisi tidak pasti (uncertainty), risiko serta kondisi pasti. Kondisi tidak pasti ialah kondisi dimana keputusan akan memiliki banyak kemungkinan dan probabilitas dari setiap kemungkinan hasil tidak diketahui. Kondisi risiko ialah kondisi dimana mungkin ada beberapa kemungkinan hasil dalam mengambil keputusan dan probabilitas hasil dapat dikira-kira oleh pengambil keputusan, dan kondisi pasti ialah kondisi di mana ada suatu hasil yang pasti saat pengambilan keputusan yang akurat (Hansson, 1994).

\section{Behavioral Finance}

Menurut Pompian (2006), behavioral finance adalah ilmu tentang cara manusia mengungkapkan serta menanggapi informasi yang tersedia, bertujuan untuk membuat keputusan yang menyempurnakan tingkat pengembalian serta memertimbangkan risiko yang ada (tindakan serta sikap individu seseorang ialah faktor penentu investasi). Behavioral finance berhubungan dengan tiga variabel yaitu herding behavior, overconviden, dan experience regret.

\section{Prospect Theory}

Menurut Edwards (1996), prospect theory ialah teori yang menjelaskan tentang bias kognitif yang memengaruhi individu dalam pengambilan keputusan ketika kondisi tidak pasti dan banyak risiko. Seseorang cenderung memiliki sifat untuk menghindari risiko atau cenderung suka dengan risiko tergantung kepada masalah yang sedang dialami. Prospect theory mengungkapkan seseorang cenderung akan memberi penilaian yang lebih tinggi terhadap hasil yang telah pasti dibanding hasil yang belum pasti. Prospect theory berhubungan dengan variabel risk perception dan illusion of control.

\section{Investasi dan Keputusan Investasi}

Menurut Tandelilin (2012), investasi ialah suatu perjanjian dengan sejumlah biaya atau sumber daya lain yang digunakan saat ini, yang mempunyai tujuan yaitu untuk mendapatkan banyak untung dimasa mendatang. Pengambilan keputusan investasi merupakan hal penting yang harus diperhatikan dalam berinvestasi.

Keputusan investasi ialah sebuah tindakan yang dilakukan seseorang ketika mengambil keputusan investasi dengan harapan untuk memperoleh untung (Budiarto, 2017). Menurut Tandelilin (2012), terdapat hal-hal yang menjadi dasar individu ketika mengambil keputusan investasi. Yang pertama adalah return, inilah alasan pertama individu melakukan kegiatan investasi. Kedua risk atau risiko. Semakin besar pengembalian yang diinginkan dari suatu investasi, semakin tinggi risiko yang didapatkan. Ketiga adalah apakah hubungan antara pengembalian dan tingkat pengembalian yang diharapkan linier atau satu arah. 


\section{Financial Literacy}

Organization for Economic Co-operation and Development (2016) menyebutkan financial literacy adalah pemahaman, pengetahuan, keterampilan terkait konsep dan risiko keuangan serta kepercayaan diri dan motivasi ketika membuat sistematika keuangan yang efektif, memajukan kesejahteraan keuangan masyarakat maupun individu, serta mengikuti kegiatan terkait perekonomian. Financial literacy merupakan suatu kegiatan yang bertujuan untuk mengembangkan pengetahuan, keyakinan dan keterampilan agar seseorang dapat mengelola keuangan dengan baik. Dengan memiliki pengetahuan tentang keuangan yang memadai, masyarakat terutama investor diharap mampu membuat suatu keputusan investasi yang tepat sesuai dengan harapan yaitu mendapatkan keuntungan (OJK, 2013).

\section{Herding Behavior}

Menurut Anindya \& Sukamulja (2017), herding behavior adalah perilaku mengikuti orang lain dan dipraktikkan oleh seseorang investor dalam mengikuti investor lain dengan macam-macam alasan. Sikap ini merupakan salah satu tindakan yang salah dan sering terjadi karena investor cenderung mengikuti orang lain ketika mengambil keputusan investasi. Alasan utama perilaku herding seorang investor ialah pengaruh dari orang-orang sekitar. Investor dengan herding attitude yang tinggi gampang dipengaruhi oleh keputusan orang lain sehingga memengaruhi perubahan keputusan investasi yang dibuat (Gozalie \& Anastasia, 2015).

\section{Risk Perception}

Menurut Irjayanti (2017), risk perception ialah suatu teori tentang proses menilai, memandang dan menginterpretasi kegiatan investor terkait suatu risiko indikator investasi tentang keputusan investasi. Masing-masing investor mempunyai metode dalam menilai risiko yang bedasatu sama lain berdasarkan faktor psikologis. Menurut Sindhu \& Kumar (2014), risk perception ialah sikap yakin, rasional maupun tidak, dikelola oleh perorangan, kelompok, serta masyarakat terkait mungkin atau tidak terjadi risiko atau terkait besar, tingkat serta waktu pengaruhnya.

\section{Overconvidence}

Menurut Pompian (2006), overconfidence ialah suatu kepercayaan yang tidak beralasan terkait kemampuan kognitif, penilaian serta penalaran intuisi seseorang. Overconfidence bermula daristudi psikologi kognitif dan keakuratan informasi yang diberikannya. Menurut Griffin \& Varey (1996), overconfidence terbagi menjadi dua tipe yaitu seseorang yang bersikap overconfidence karena terlalu percaya akan pengetahuan yang dimiliki dan dikarenakan terlalu percaya diri akan kemampuan dirinya.

\section{Experience Regret}

Experience regret adalah suatu keadaan yang timbul dalam diri seseorang pada saat mengambil keputusan investasi atau mengambil risiko sebagai akibat dari ketetapan sebelumnya sehingga menimbulkan penyesalan dan kekecewaan. Hal tersebut akan membuat seseorang lebih berhati-hati untuk melakukan investasi pada jenis investasi yang memiliki return yang tinggi pada risiko yang tinggi pula, serta akan menghitung risiko-risiko yang akan muncul dari akibat investasi yang telah dipilih. Sehingga dapat dikatakan orang dengan experience regret akan cenderung memilih jenis investasi yang memiliki risiko yang rendah dikarenakan telah memiliki pengalaman yang kurang baik dalam pengambilan investasi (Yohnson, 2008).

\section{Illusion Of Control}

Menurut Langer (1975), illusion of control ialah harapan pada probabilitas terhadap keberhasilan pada individu yang secara tidak langsung lebih tinggi dibanding probabilitas obyektif yang pasti. Menurut Pompian (2006), illusion of control ialah rasa percaya jika individu mampu mengontrol atau memengaruhi hasil, namun pada realitanya tidak. Investor yang memiliki sikap illusion of control lebih menyukai saham dibandingkan obligasi, karena memiliki risiko yang tinggi dan mereka tidak dapat mengendalikan perilakunya. 


\section{Hubungan antar Variabel}

Menurut Budiarto (2017), seseorang yang mempunyai pengetahuan tentang informasi keuangan yang cukup, sehingga bisa membuat keputusan investasi yang sesuai dengan apa yang diharapkan. Menurut Pradikasari \& Isbanah (2018), seseorang yang mempunyai financial literacy tinggi, dengan pendapatan yang dimiliki diinvestasikan pada banyak jenis investasi dengan mengetahui risiko yang terjadi. Tingkat literasi keuangan seseorang semakin tinggi, maka semakin cerdas individu dapat membuat keputusan investasi (Pradhana, 2018).

\section{H1: Financial literacy berpengaruh terhadap keputusan investasi mahasiswa.}

Investor dengan perilaku herding yang tinggi sering membuat keputusan investasi mengikuti investor lain. Sikap herding bisa berupa keadaan mengikuti keputusan investasi pada rekan investasi, mitra investasi, investor terkemuka, professional investasi (Mutawally \& Haryono, 2019). Berdasarkan hasil penelitian Khairunizam \& Isbanah (2019) dan Putri \&Isbanah (2020) menunjukkan herding behavior memengaruhi keputusan investasi.

H2: Herding behavior berpengaruh terhadap keputusan investasi mahasiswa.

Risk perception adalah cara pandang individu terhadap situasi berisiko, berdasarkan karakteristik dan keadaan psikologis individu (Wulandari \& Iramani, 2014). Aren \& Zengin (2016) menyatakan risk perception memengaruhi tingkat selera investasi individu. Investor yang menyukai risiko maka memprioritaskan memilih investasi pada valuta asing, portofolio serta modal, namun investor yang menjauhi risiko maka lebih memilih investasi pada deposito.

H3: Risk perception berpengaruh terhadap keputusan investasi mahasiswa.

Kondisi emosi dari psikologi investor juga dapat memengaruhi pengambilan keputusan. Overconfidence adalah suatu kondisi dimana investor cenderung terlalu yakin terhadap kemampuan dan pengetahuannya dalam mengambil keputusan (Afriani \& Halmawati, 2019). Overconfidence membuat seseorang melebih-lebihkan pengetahuan dan kemampuan, serta meremehkan risiko dalam mengkontrol apa yang terjadi. Penelitian oleh Budiarto (2017), Khairunizam \& Isbanah (2019), dan Pradikasari \& Isbanah (2018) menyatakan overconvidence memiliki pengaruh terhadap keputusan berinvestasi.

\section{H4: Overconfidence berpengaruh terhadap keputusan investasi mahasiswa.}

Investor berpengalaman tidak selalu memertimbangkan dan menimbang semua faktor sebelum mengambil keputusan investasi. Semakin berpengalaman seorang investor, semakin profesional investor dalam membuat keputusan investasi yang menguntungkan di kemudian hari. Investor dengan pengalaman memilih saham dengan risiko yang tinggi akan lebih berani dalam membuat keputusan di saham dengan risiko tinggi di kemudian hari (Mutawally \& Haryono, 2019). Hasil penelitian oleh Wulandari \& Iramani (2014) dan Novianggie \& Asandimitra (2019) menyatakan experience regret tidak memengaruhi keputusan berinvestasi.

\section{H5: Experience regret berpengaruh terhadap keputusan investasi mahasiswa.}

Investor cenderung optimis dengan hasil keputusan investasi yang diambil, hal ini menimbulkan asumsi bahwa keputusan investasi yang diberi ialah rasional. Apabila investor dengan sikap illusion of control tinggi, artinya investor yakin dengan perilaku dalam mengambil keputusan yang diterima. Sikap ini berpotensi meningkatkan kepercayaan investor melalui pengalaman dan menghilangkan keraguan dalam mengambil keputusan dan mengelola keadaan dimasa mendatang (Mutawally \& Haryono, 2019). Berdasarkan hasil penelitian Kartini \& Nugraha (2015) dan Pradhana (2018) illusion of control memengaruhi keputusan berinvestasi.

\section{H6: Illusion of control berpengaruh terhadap keputusan investasi mahasiswa.}




\section{METODE PENELITIAN}

Penelitian ini menggunakan pendekatan kausal. Data primer diperoleh dari kuesioner. Variabel terdiri dari variabel dependen dan independen. Variabel independen meliput financial literacy, herding behavior, risk perception, overconvidence, experience regret, dan illusion of control. Variabel dependen adalah keputusan investasi. Populasi adalah mahasiswa dengan kriteria memiliki rekening efek dan terdaftar dalam Galeri Investasi di Universitas Nusantara PGRI Kediri. Sampel diperoleh menggunakan teknik purposive sampling melalui kuesioner yang disebar melalui sosial media. Kriteria pemilihan sampel yaitu mahasiswa yang tergabung dan memiliki rekening efek di Galeri Investasi Universitas Nusantara PGRI Kediri dan pernah melakukan transaksi di pasar modal. Penelitian ini menggunakan jumlah sampel sebanyak 100 responden di galeri investasi Universitas Nusantara PGRI Kediri.Teknik analisis data menggunakan SEM PLS dengan langkah uji validitas konvergen, uji Average Variance Extracted (AVE), uji validitas diskriminan, uji Cronbach's Alpha dan compsite reliability, serta Uji R-Square $\left(\mathrm{R}^{2}\right)$.

\section{HASIL DAN PEMBAHASAN}

\section{Karakteristik Responden}

Berdasarkan kuesioner yang telah disebar, responden yang menjawab pertanyaan yaitu laki-laki sebesar 33,3\% atau 37 responden, sedangkan responden perempuan berjumlah 66,7\% atau 74 orang. Sesuai kriteria yang telah ditetapkan, investor yang menjadi responden yaitu investor yang telah melaksanakan transaksi di pasar modal, baik hanya sekali atau lebih. Berdasarkan dari data Galeri Investasi Universitas Nusantara PGRI Kediri menunjukkan bahwa mahasiswa yang menjadi anggota Galeri Investasi hanya berasal dari Universitas Nusantara PGRI Kediri sehingga seluruh responden yang menjawab kuesioner adalah mahasiswa dari Universitas Nusantara PGRI Kediri.

\section{Uji Outer Loading}

Hasil uji validitas diketahui bahwa setelah dilakukan uji outer loading terdapat satu item pernyataan yang tidak valid yaitu X6.1, sehingga item pertanyaan dihilangkan karena tidak valid. Namun, untuk 36 item pernyataan yang lain memiliki nilai di atas 0,5 dinyatakan valid dan dapat digunakan untuk melakukan pengukuran pengaruh financial literacy, herding behavior, risk perception, experience regret, dan illusion of control terhadap keputusan investasi.

Tabel 1.

AVERAGE VARIANCE EXTRACTED

\begin{tabular}{lc}
\hline & Average Variance Extracted (AVE) \\
\hline Experience Regret & 0,784 \\
Financial Literacy & 0,533 \\
Herding Behavior & 0,789 \\
Illusion Of Control & 0,550 \\
Keputusan Investasi & 0,666 \\
Overconvidence & 0,548 \\
Risk Perception & 0,685 \\
\hline Sumber: Output SmartPLS (2021, data diolah)
\end{tabular}

\section{Uji AVE}

Sesuai Tabel 1, nilai AVE berada di atas 0,5 sehingga dapat dikatakan indikator yang digunakan adalah alat ukur yang tepat untuk mengukur variabel.

\section{Uji Discriminant Validity}

Nilai discriminant validity berada di atas 0,7 sehingga validitas pada penelitian adalah baik.

\section{Uji Cronbach's Alpha dan Compsite Reliability}

Tabel 2 menunjukkan nilai Cronbach's Alpha dan Compsite Reliability di atas 0,7. Artinya, ada konsistensi dari alat ukur yang dipakai di penelitian dan konstruk mempunyai reliabilitas yang baik. 


\section{Uji R-Square}

Nilai R-square sebesar 0,875 yang artinya mempunyai nilai lebih besar dari 0,67 sehingga model yang dibuat merupakan model yang baik.

Tabel 2.

CRONBACH'S ALPHA DAN COMPSITE RELIABILITY

\begin{tabular}{lcc}
\hline \multicolumn{1}{c}{ Variabel } & Cronbach's Alpha & Composite Reliability \\
\hline Experience Regret & 0,908 & 0,936 \\
Financial Literacy & 0,884 & 0,899 \\
Herding Behavior & 0,910 & 0,937 \\
Illusion Of Control & 0,799 & 0,856 \\
Keputusan Investasi & 0,831 & 0,888 \\
Overconvidence & 0,595 & 0,783 \\
Risk Perception & 0,846 & 0,896 \\
\hline
\end{tabular}

Sumber: Output SmartPLS (2021, data diolah)

Tabel 3.

PATH COEFISIENTS

\begin{tabular}{|c|c|c|c|c|}
\hline Hubungan antarVariabel & $\begin{array}{c}\text { Original } \\
\text { Sample }(\mathrm{O})\end{array}$ & $\begin{array}{c}\text { Standard Deviation } \\
\text { (STDEV) }\end{array}$ & $\begin{array}{c}\text { T Statistics } \\
(|\mathrm{O} / \mathrm{STDEV}|) \\
\end{array}$ & $P$ Values \\
\hline $\begin{array}{l}\text { experience } \\
\text { regret } \rightarrow \text { keputusan investasi } \\
\text { financial }\end{array}$ & $-0,001$ & 0,102 & 0,006 & 0,995 \\
\hline $\begin{array}{l}\text { literacy } \rightarrow \text { keputusan } \\
\text { investasi } \\
\text { herding }\end{array}$ & 0,697 & 0,192 & 3,620 & 0,000 \\
\hline $\begin{array}{l}\text { behavior } \rightarrow \text { keputusan } \\
\text { investasi }\end{array}$ & $-0,135$ & 0,071 & 1,916 & 0,056 \\
\hline $\begin{array}{l}\text { illusion of } \\
\text { control } \rightarrow \text { keputusan } \\
\text { investasi }\end{array}$ & 0,640 & 0,110 & 5,819 & 0,000 \\
\hline $\begin{array}{l}\text { overconvidence } \rightarrow \text { keputusan } \\
\text { investasi }\end{array}$ & $-0,428$ & 0,086 & 4,979 & 0,000 \\
\hline $\begin{array}{l}\text { risk perception } \rightarrow \text { keputusan } \\
\text { investasi }\end{array}$ & 0,011 & 0,103 & 0,103 & 0,918 \\
\hline
\end{tabular}

Sumber: Output SmartPLS (2021, data diolah)

Tabel 3 menunjukkan nilai original sample financial literacy sebesar 0,696 yang artinya bahwa arah hubungan variabel financial literacy terhadap variabel keputusan investasi adalah positif. Nilai $P$. Values sebesar 0,000 menunjukkan $\mathrm{H} 1$ terbukti. Jadi financial literacy berpengaruh signifikan positif terhadap keputusan investasi. Nilai original sample herding behavior sebesar -0,135 yang artinya arah hubungan variabel herding behavior terhadap variabel keputusan investasi adalah negatif. Nilai $P$. Values sebesar 0,056 menunjukkan $\mathrm{H} 2$ ditolak. Jadi herding behavior tidak berpengaruh signifikan negatif terhadap keputusan investasi. Nilai original sample risk perception sebesar 0,011yang artinya arah hubungan variabel risk perception terhadap variabel keputusan investasi adalah positif. Nilai $P$. Values sebesar 0,918 menunjukkan H3 ditolak. Jadi risk perception tidak berpengaruh signifikan positif terhadap keputusan investasi. Nilai original sample overconvidence sebesar -0,428 yang artinya arah hubungan variabel overconvidence terhadap variabel keputusan investasi adalah negatif. Nilai $P$. Values sebesar 0,000 menunjukkan $\mathrm{H} 4$ diterima. Jadi overconvidence berpengaruh signifikan negatif terhadap keputusan investasi. Nilai original sample experience regret sebesar $-0,001$ yang artinya arah hubungan variabel experience regret terhadap variabel keputusan investasi adalah negatif. Dan nilai $P$. Values sebesar 0,995 menunjukkan H5 ditolak. Jadi experience regret tidak berpengaruh signifikan negatif terhadap keputusan investasi. Nilai original sample illusion of control sebesar 0,640 yang artinya arah hubungan variabel illusion of control terhadap variabel keputusan 
investasi adalah positif. Nilai $P$. Values sebesar 0,000 menunjukkan H6 diterima. Jadi illusion of control berpengaruh signifikan positif terhadap keputusan investasi.

\section{Pengaruh Financial Literacy terhadap Keputusan Investasi}

Berdasarkan hasil analisis statistik, variabel financial literacy memengaruhi keputusan berinvestasi dengan nilai original sample menunjukkan nilai positif yang artinya bahwa arah hubungan variabel financial literacy terhadap variabel keputusan investasi adalah positif. Dengan demikian, H1 terbukti. Hasil ini sesuai dengan decition theory yang menyatakan pengambilan keputusan tiga kondisi dan situasi yaitu kondisi ketidakpastian (uncertainty), berisiko, dan kepastian. Hasil penelitian ini mendukung Wardani \& Lutfi(2019) dan Novianggie \& Asandimitra (2019) menyatakan financial literacy memengaruhi keputusan berinvestasi. Hasil penelitian membuktikan financial literacy menjadi hal yang dibutuhkan dalam memulai investasi dan menjadi faktor yang paling diperhatikan sebelum memutuskan investasi yang akan diambil. Financial literacy digunakan untuk menghindari serta mencegah hal-hal yang nantinya akan memberi kerugian dan mengejar keuntungan ketika berinvestasi. Dalam hal ini, investor perlu memperbanyak literasi mengenai informasi dan belajar mengenai investasi agar faktor ini dapat digunakan untuk menghindari serta mencegah hal-hal yang nantinya akan memberi kerugian dan mengejar keuntungan ketika memulai berinvestasi.

\section{Pengaruh Herding Behavior terhadap Keputusan Investasi}

Hasil analisis statistik variabel herding behavior tidak memengaruhi keputusan berinvestasi dengan nilai original sample menunjukkan nilai negatif yang artinya bahwa arah hubungan variabel herding behavior terhadap variabel keputusan investasi adalah negatif. Dengan demikian, H2 ditolak. Hasil ini kurang sesuai dengan behavioral finance menyatakan terdapat peranemosi, sifat, preferensi dan keberagaman yang terdapat pada individu sebagai makhluk sosial dan intelektual mendasari munculnya keputusan investasi. Hasil penelitian sebanding dengan penelitian terdahulu oleh Setiawan et al. (2018) dan Salerindra (2020) menyatakan herding behavior tidak memengaruhi keputusan berinvestasi. Hal ini menunjukkan jika mahasiswa sebagai investor tidak memiliki perilaku herding yang tinggi dibuktikan dengan hasil penelitian yang menunjukkan variabel herding behavior tidak memengaruhi keputusan berinvestasi.

\section{Pengaruh Risk Perception terhadap Keputusan Investasi}

Hasil analisis statistik variabel risk perception tidak memengaruhi keputusan berinvestasi dengan nilai original sample menunjukkan nilai positif yang artinya bahwa arah hubungan variabel risk perception terhadap variabel keputusan investasi adalah positif. Dengan demikian, H3 tidak terbukti. Temuan penelitian tidak sesuai dengan prospect theory menjelaskan adanya bias kognitif memengaruhi ketika mengambil keputusan dalam kondisi tidak pasti dan risiko. Hasil penelitian sebanding dengan penelitian terdahulu oleh Putri \& Isbanah (2020), Khairunizam \& Isbanah (2019) dan Pradikasari \& Isbanah (2018) menunjukkan risk perception tidak memengaruhi keputusan investasi. Hal ini dikarenakan tiap investor memiliki pandangan masing-masing dalam memulai dan menjalankan investasi. Beberapa investor memilih saham yang memiliki risiko pasti dan ada juga yang memilih risiko tidak pasti sehingga dalam mengambil keputusan investasi risk perception tidak memengaruhi keputusan berinvestasi. Investor sering mengabaikan risk perception saat mengambil keputusan berinvestasi karena tidak banyak memertimbangkan ketika mengambil keputusan investasi dan tidak berhati-hati serta lebih berani saat mengambil keptusan investasi.

\section{Pengaruh Overconvidence terhadap Keputusan Investasi}

Hasil analisis statistik variabel overconvidence memengaruhi keputusan berinvestasi dengan nilai original sample menunjukkan nilai negatif yang artinya bahwa arah hubungan variabel overconvidence terhadap variabel keputusan investasi adalah negatif. Dengan demikian, H4 dapat dibuktikan dalam penelitian ini. Hasil penelitian ini sesuai dengan behavioral finance yang menyatakan cara manusia bereaksi dan mengambil sikap terhadap informasi untuk mengambil keputusan yang dapat mengoptimalkan pendapatan dengan memperhitungkan risiko yang melekat pada informasi. Hasil penelitian ini mendukung Budiarto (2017), Khairunizam \& Isbanah (2019) dan Pradikasari \& Isbanah (2018) yang menyatakan overconvidence mempunyai pengaruh terhadap keputusan berinvestasi. Hasil penelitian ini menentukan sikap yang dapat diambil oleh investor dalam 
memutuskan investasi dengan memperhatikan risiko-risiko yang akan dihadapi ketika berinvestasi. Untuk menyikapi keputusan yang diambil dalam berinvestasi, investor perlu memiliki kepastian dan informasi yang cukup dalam mengambil keputusan dengan memperhatikan risiko didalamnya karena investasi bisa memberikan umpan balik berbagai macam yang pastinya bisa membuat reaksi investor berbeda-beda.

\section{Pengaruh Experience Regret terhadap Keputusan Investasi}

Hasil analisis statistik variabel experience regret tidak memengaruhi keputusan investasi dengan nilai original sample menunjukkan nilai negatif yang artinya bahwa arah hubungan variabel experience regret terhadap variabel keputusan investasi adalah negatif. Dengan demikian, H5 ditolak. Temuan tersebut tidak sesuai dengan behavioral finance yang menyatakan cara menggunakan informasi untuk membuat keputusan yang mengoptimalkan keuntungan dengan memertimbangkan risiko yang ada. Hasil penelitian sebanding dengan penelitian terdahulu oleh Wulandari \& Iramani (2014) dan Novianggie \& Asandimitra (2019) menyatakan experience regret tidak memengaruhi keputusan investasi. Hal ini disebabkan investor sedikit mempunyai investasi dengan risiko yang rendah sehingga pengalaman berinvestasi yang dialami investor tidak memengaruhi dalam memutuskan untuk berinvestasi.

\section{Pengaruh Illusion Of Control terhadap Keputusan Investasi}

Hasil analisis statistik variabel illusion of control memengaruhi keputusan investasi dengan nilai original sample menunjukkan nilai positif yang artinya bahwa arah hubungan variabel illusion of control terhadap variabel keputusan investasi adalah positif. Dengan demikian, H6 diterima. Temuan ini seimbang dengan prospect theory yang menyatakan munculnya bias kognitif memengaruhi pengambilan keputusan dalam kondisi tidak pasti serta berisiko. Hasil penelitian ini sesuai dengan Pradhana (2018) dan Kartini \& Nugraha (2015) yang menyatakan illusion of control memengaruhi keputusan berinvestasi. Hasil temuan digunakan sebagai sikap agar investor lebih berhati-hati ketika menentukan keputusan untuk berinvestasi. Hal ini karena kepercayaan atas kemampuan diri seorang investor dapat memicu hasil investasi yang telah diambil. Disaat investor merasa bahwa suatu investasi memiliki risiko kerugian maka tidak akan diambil namun ketika yakin melihat keuntungan maka dapat melanjutkan investasinya.

\section{KESIMPULAN}

Financial literacy, overconviden, dan illusion of control memengaruhi pengambilan keputusan investasi pada mahasiswa di Kediri. Financial literacy menjadikan investor mendapat lebih banyak menggali literasi mengenai informasi dan belajar mengenai investasi agar dapat digunakan untuk menghindari serta mencegah risiko yang kemungkinan ditemui. Overconvidence menjadikan investor memiliki kepastian dan informasi yang cukup dalam mengambil keputusan dengan memerhatikan risiko didalamnya untuk mempersiapkan diri dalam menerima timbal balik dari investasi yang dijalani. Illusion of control menjadikan investor percaya atas kemampuan diri yang nantinya dapat memicu hasil investasi yang telah diambil dengan keputusan yang pasti. Hal ini membuktikan bahwa mahasiswa dengan pengetahuan keuangan yang lebih baik dapat membuat keputusan berinvestasi yang baik. Herding behavior, risk perception, dan experience regret tidak memengaruhi pengambilan keputusan investasi mahasiswa di Kediri.

Populasi maupun sampel yang digunakan mempunyai batasan yaitu keberagaman investor sebab hanya pada ruang lingkup Galeri Investasi Bursa Efek Indonesia Universitas Nusantara PGRI Kediri. Penelitian selanjutnya direkomendasikan menambah jumlah responden dari beberapa Galeri Investasi dan melibatkan variabel regret aversion bias, risk tolerance, loss aversion, cognitive dissonance, cognitive bias, financial behavior, dan variabel lainnya yang berkaitan dengan keputusan investasi.

\section{DAFTAR PUSTAKA}

Afriani, D., \& Halmawati. (2019). Pengaruh Cognitive Dissonance Bias, Overconfidence Bias dan 
Lilis Ayudiastuti. Analisis Pengaruh Keputusan Investasi Mahasiswa

Herding Bias terhadap Pengambilan Keputusan Investasi (Studi Empiris pada Mahasiswa Fakultas Ekonomi Universitas Negeri Padang yang Melakukan Investasi di Bursa Efek Indonesia). Jurnal Eksplorasi Akuntansi, 1(4), 1650-1665. http://jea.ppj.unp.ac.id/index.php/jea/issue/view/14

Anindya, W. K., \& Sukamulja, J. S. (2017). Perilaku Herding Pada Indeks Sektoral dan SahamSaham Terpilih. Mycological Research, 9, 207-221.

Aren, S., \& Zengin, A. N. (2016). Influence of Financial Literacy and Risk Perception on Choice of Investment. Procedia - Social and Behavioral Sciences, 235(October), 656-663. https://doi.org/10.1016/j.sbspro.2016.11.047

Bakar, S., \& Yi, A. N. C. (2016). The Impact of Psychological Factors on Investors' Decision Making in Malaysian Stock Market: A Case of Klang Valley and Pahang. Procedia Economics and Finance, 35(May), 319-328. https://doi.org/10.1016/s2212-5671(16)00040-x

Bisnis.com. (2020). Investor Pasar Modal di Jatim Naik 25 Persen. surabaya.bisnis.com (https://surabaya.bisnis.com/read/20200227/532/1206738/investor-pasar-modal-di-jatim-naik25-persen, diakses pada 12 Juli 2021)

Budiarto, A. (2017). Pengaruh Financial Literacy, Overconfidence, Regret Aversion Bias, dan Risk Tolerance terhadap Keputusan Investasi (Studi pada investor PT. Sucorinvest Central Gani Galeri Investasi BEI Universitas Negeri Surabaya). Jurnal Ilmu Manajemen (JIM), 5(2), 1-9.

Chin, W. W. (1998). Issues and Opinion on Structural Equation Modeling. MIS Quarterly: Management Information Systems, 22(1), 7-16.

DJKN. (2021). Aktivitas Pasar Modal Indonesia di Era Pandemi. www.djkn.kemenkeu.go.id(https://www.djkn.kemenkeu.go.id/artikel/baca/13817/AktivitasPasar-Modal-Indonesia-Di-Era-Pandemi.html, diakses pada 24 Juni 2021)

Edwards, K. D. (1996). Prospect Theory: A Literature Review. International Review of Financial Analysis, 5(1), 19-38. https://doi.org/10.1016/S1057-5219(96)90004-6

Gozalie, S., \& Anastasia, N. (2015). Pengaruh Perilaku Heuristics dan Herding terhadap Pengambilan Keputusan Investasi Properti Hunian. Finesta, 3(2), 28-32.

Griffin, D. W., \& Varey, C. A. (1996). Towards a Consensus on Confirmation.Studia Liturgica, 26(2), 190-201. https://doi.org/10.1177/003932079602600206

Hansson. (1994). Decision theory. The Cambridge History of Moral Philosophy, 706-717. https://doi.org/10.1017/9781139519267.054

Irjayanti. (2017). Pengaruh Literasi Keuangan, Representativeness, Familiarity, dan Persepsi Risiko terhadap Pengambilan Keputusan Investasi pada Investor Surabaya dan Sidoarjo. Jurnal Ilmu Manajemen, 5(9), 1-17.

Kartini, K., \& Nugraha, N. F. (2015). Pengaruh Illusions of Control, Overconfidence dan Emotion terhadap Pengambilan Keputusan Investasi pada Investor di Yogyakarta. Ajie, 4(2), 114-122. https://doi.org/10.20885/ajie.vol4.iss2.art6

Khairunizam, \& Isbanah, Y. (2019). Pengaruh Financial Literacy dan Behavioral Finance Factors terhadap Keputusan Investasi (Studi terhadap Investor Saham Syariah pada Galeri Investasi Syariah UIN Sunan Ampel Surabaya). Jurnal Ilmu Manajemen Fakultas Ekonomi Universitas Negeri Surabaya, 7(2), 516-528. 
Langer, E. J. (1975). The Illusion of Control. Journal of Personality and Social Psychology, 32(2), 311-328. https://doi.org/10.1037/0022-3514.32.2.311

Liputan6.com. (2019). Kinerja IHSG Tumbuh 4 Persen pada Kuartal I 2019. www.liputan6.com(https://www.liputan6.com/saham/read/3933422/kinerja-ihsg-tumbuh-4persen-pada-kuartal-i-2019, diakses pada 22 Juni 2021)

Lliyd, B. (1976). The Role of Capital Market in Developing Countries. Spring The Mortgage and Wall Street. Intereconomics, 12(3), 96-102.

Mutawally, F. W., \& Haryono, N. A. (2019). Pengaruh Financial Literacy, Risk Perception, Behavioral Finance dan Pengalaman Investasi terhadap Keputusan Investasi Mahasiswa Surabaya. Jurnal Ilmu Manajemen (JIM), 7(4), 942-953.

Novianggie, V., \& Asandimitra, N. (2019). The Influence of Behavioral Bias, Cognitive Bias, and Emotional Bias on Investment Decision for College Students with Financial Literacy as the Moderating Variable. International Journal of Academic Research in Accounting, Finance and Management Sciences, 9(2), 92-107. https://doi.org/10.6007/IJARAFMS/v9-i2/6044

OJK. (2013). OJK Dorong Edukasi Keuangan Masyarakat Melalui Kampus. www.ojk.go.id(https://www.ojk.go.id/id/berita-dan-kegiatan/siaran-pers/Pages/ojk-dorongedukasi-keuangan-masyarakat-melalui-kampus.aspx, diakses pada 5 November 2020)

OJK. (2015).

Ikhtiar

Tingkatkan

Literasi

Keuangan. www.ojk.go.id(https://sikapiuangmu.ojk.go.id/FrontEnd/CMS/Download/15, diakses pada 5 November 2020)

OJK. (2018). Siaran Pers: OJK Dorong Masyarakat Punya Sikap Keuangan (Financial Attitudes). www.ojk.go.id(https://www.ojk.go.id/id/berita-dan-kegiatan/siaran-pers/Pages/Siaran-PersOJK-Dorong-Masyarakat-Punya-Sikap-Keuangan-Financial-Attitudes.aspx, diakses pada 5 November 2020)

Pompian, M. M. (2006). Behavioral Finance and Wealth Management: How to Build Optimal Portfolios That Account for Investor Biases (First). John Wiley \& Sons, Inc, 101 CHF, 318 pages

Pradhana, R. W. (2018). Pengaruh Financial Literacy, Cognitive Bias, dan Emotional Bias terhadap Keputusan Investasi (Studi Pada Investor Galeri Investasi Universitas Negeri Surabaya). Jurnal Ilmu Manajemen (JIM), 6(3), 108-117.

Pradikasari, E., \& Isbanah, Y. (2018). Pengaruh Financial Literacy, Illusion of Control, Overconfidence, Risk Tolerance, dan Risk Perception terhadap Keputusan Investasi pada Mahasiswa di Kota Surabaya. Jurnal Ilmu Manajemen (JIM), 6(4), 424-434.

Putra, I. P. S., Ananingtiyas, H., Sari, D. R., Dewi, A. S., \& Silvy, M. (2016). Experienced Regret , dan Risk Tolerance pada Pemilihan Jenis Investasi. Journal of Business and Banking, 5(2), 271-282. https://doi.org/10.14414/jbb.v5i2.548

Putri, R. A., \& Yuyun, I. (2020). Faktor-Faktor Yang Mempengarui Keputusan Investasi pada Investor Saham di Surabaya. Jurnal Ilmu Manajemen, 8(1), 197-209.

Salerindra, B. (2020). Determinan Keputusan Investasi Mahasiswa pada Galeri Investasi Perguruan Tinggi di Surabaya dan Malang. Jurnal Ilmu Manajemen, 8(1), 157-173.

Sarwono, J., \& Narimawati, U. (2015). Membuat Skripsi, Tesis dan Disertasi dengan Partial Least 
Lilis Ayudiastuti. Analisis Pengaruh Keputusan Investasi Mahasiswa

Square SEM (PLS-SEM). Yogyakarta : ANDI.

Setiawan, Y. C., Atahau, A. D. R., \& Robiyanto, R. (2018). Cognitive Dissonance Bias, Overconfidence Bias dan Herding Bias dalam Pengambilan Keputusan Investasi Saham. AFRE (Accounting and Financial Review), 1(1), 17-25. https://doi.org/10.26905/afr.v1i1.1745

Sindhu, K., \& Kumar, S. R. (2014). Influence of Risk Perception of Investors on Investment Decisions. Journal of Finance and Accounting, 2(2), 15-25.

Tandelilin, E. (2012). Dasar-dasar Manajemen Investasi. Manajemen Investasi, 1-34, Yogyakarta: Kanisius.

Wardani, A. K., \& Lutfi, L. (2019). Pengaruh Literasi Keuangan, Experienced Regret, Risk Tolerance, dan Motivasi pada Keputusan Investasi Keluarga dalam Perspektif Masyarakat Bali. Journal of Business \& Banking, 6(2), 195-214. https://doi.org/10.14414/jbb.v6i2.996

Wulandari, D. A., \& Iramani, R. (2014). Studi Experienced Regret, Risk Tolerance, Overconfidance Dan Risk Perception Pada Pengambilan Keputusan Investasi. Journal of Business and Banking, 4(1), 55. https://doi.org/10.14414/jbb.v4i1.293

Yohnson. (2008). Regret Aversion Bias dan Risk Tolerance Investor Muda Jakarta dan Surabaya. Jurnal Manajemen Dan Kewirausahaan, 10(2), 163-168. https://doi.org/10.9744/jmk.10.2.pp.163-168 